\title{
TELEVISÃO: DESAFIO PERMANENTE
}

Ainda me lembro do dia em que meu pai disse: "começou a funcionar um 'aparelho' que permite que a gente veja o que está acontecendo 'do lado de lá' do rádio que estamos ouvindo". E eu, imediatamente, fanática pela Rádio Nacional do Rio de Janeiro como qualquer menina do Interior de São Paulo, pensei - que bom! agora vou poder ver (e conversar) com a Emilinha Borba.

Era o início da década de 50 e Assis Chateaubriand iniciava aqui a televisão. Em 1965 começa a Rede Globo e em uma geração apenas a televisão tomou conta do Brasil.

A análise da televisão, como de resto dos demais meios de comunicação, já passou pelas fases dos "apocalíticos" (os que consideravam e/ou consideram que os meios de comunicação alienam para todo o sempre a sociedade) e dos "integrados" (os que acabam por manifestar em sua atitude a concepção do "relaxa e aproveita").

Evidentemente, como qualquer maniqueísmo, ambos os pólos, separadamente, são desastrosos. Pensamos, porém, que têm se justificado sobretudo pelo déficit de pesquisas que colaborem para configurar, cientificamente, as posições. O que se fez, durante largo tempo, foi aplicar as grandes teorias à nossa realidade, sem a devida adequação.

Hoje a televisão está em todos os lares, chega a todas as famílias, detém o poder de agendar os temas a serem discutidos pela sociedade. Apropriou-se de novas tecnologias, o que lhe permite uma performance de melhor qualidade e de mais longo alcance.

Atua com notícia, a "verdade", trazida em uma variedade de modelos de programas: dos telejornais tradicionais às grandes reportagens temáticas e/ou específicas de segmentos da sociedade (rural, por exemplo). Também atua com ficção, o apenas "verossí-

\section{A AUTORA}

Maria Aparecida Baccega

Professora Doutora do Departamento de Comunicações e Artes da ECA-USP. Especialista em Linguagem Verbal nos Meios de Comunicação. Autora de Concordância Verbal; Artigo e Crase e Palavra e Discurso. 
mil", como as telenovelas, minisséries, unitários etc. Imbrica essas duas naturezas: tem muita "verossimilhança" nos noticiários e tem muita "verdade" na ficção ${ }^{1}$. Também passou a ser usada na educação. Entre outros, podemos destacar o Projeto TV Escola ${ }^{2}$. Isso, para não falarmos que a televisão educa permanentemente, quer queiramos ou não.

Podemos perceber que a televisão se banalizou. O que não significa que ela tenha banalizado sua importância. Pelo contrário: tornou-se objeto de análise ainda mais complexo. Segundo Dominique Wolton, diretor do Laboratório de Comunicação e Política do CNRS (Centre National de Recherches Scientifiques), de Paris, estamos diante de uma nova partição, que aprofunda o desafio: "a televisão generalista e a televisão fragmentada".

Na primeira, a programação procura "satisfazer a diferentes públicos, constrói uma grade de ofertas suscetível de gerar múltiplas expectativas: é a idéia do menu". Na segunda, prevalece "o programa singular que cada espectador escolhe assistir, sem que tenham qualquer ligação uns com os outros". É a televisão à la carte (.....)"3.

Com a entrada da TV a cabo, a televisão à la carte ampliou grandemente sua oferta: é bem maior o número de opções. Para preencher a programação de todos esses canais, é preciso um volume muito grande de produção audiovisual. Essa produção se apresenta, muitas vezes, com qualidade e valores que nem sempre resistem à análise mais elementar.

Isso faz retornar, com mais força, a antiga discussão: os valores que nos são passados pelos programas de outros países são estranhos à nossa cultura e, portanto, "alienam", pois colaboram para a perda da identidade nacional. Desse modo, instala-se mais um desafio, de que só a corrida contra o tempo poderá dar conta. Vejamos.

Se temos claro que formamos a nossa identidade a partir do confronto com o outro, então os programas de outras partes do mundo não terão esse poder. Afinal, eles serão vistos por nós como ratificação de nossa própria identidade, fazendo sobrelevar as marcas que nos diferem dos demais. No entanto, para que seja assim, é preciso que tenhamos medianamente claro o que nos caracteriza. Será que temos uma formação suficientemente sólida que nos permite circular pelo mundo "antropofagicamente"?

A realidade contemporânea, porém, não nos pediu licença para se configurar e nem nos dará outro tempo para nos aprumarmos. Por isso, compete-nos formar, rapidamente, cidadãos críticos, capazes de mobilizar conhecimentos que se manifestem como critérios culturais de identificação de seus valores. Este, o maior de todos os desafios.

1. Este é um dos pontos da discussão sobre televisão que se encontra publicado em duas edições, na seção Artigo Internacional, com o título Televisão como mito e ritual. Comunicação \& Educação. n. 1, set/dez de 1994; n.2, jan/abr de 1995.

2. Projeto TV Escola: Isa Grinspum Ferraz. Entrevista de Roseli Fígaro. Comunicação \& Educação. n.6, mai/ago de 1996. p.58-68.

3. WOLTON, Dominique. Elogio do grande público. Uma teoria crítica da televisão. (Trad. José Rubens Siqueira). São Paulo: Ática, 1996. p.100-101. 


\section{ARTIGOS NACIONAIS}

Mauro Pereira Porto, em $O$ poder da televisão: relações entre TV e política, colabora para pensarmos o desafio. Segundo o autor, a visão de mundo que antes era constituída a partir da modalidade escrita da linguagem, hoje está sendo substituída por aquilo que o homem vê na televisão. "Em todo o mundo, a televisão aparece como a principal fonte de informação das pessoas sobre o que acontece na política". No Brasil esse índice vai de $86 \%$ a $89 \%$ da população.

E isso não apenas nos programas denominados políticos ${ }^{4}$. A educação política pela televisão está em toda a programação. Inclusive, e em alguns casos sobretudo, nas telenovelas. É o que lembra o autor. Como dissemos, é a fusão da "verossimilhança" com a "verdade".

Todo cuidado é pouco. É o que lembra Nélson Hoineff, em Burrice cresce na TV por assinatura.

Segundo o autor, o aumento da oferta de canais parece caminhar para o aumento do "lixo da TV", com "canais que não interessam a ninguém".

$\mathrm{Na}$ área da educação, a ordenação advém da Lei de Diretrizes e Bases. Ismar de Oliveira Soares, Coordenador do Núcleo de Comunicação e Educação, havia feito a análise do projeto aprovado pela Câmara ${ }^{5}$, e que estava em tramitação no Senado, onde foi bastante modificado. Como ficou, agora, a inter-relação Comunicação/Educação, campo de vital importância para a formação da cidadania? Muitos leitores nos solicitaram essa atualização. É o que encontramos em Lei de Diretrizes e Bases e a Comunicação no sistema de ensino.

Segundo Ismar, a nova proposta permite afirmar que, "ainda que sem a mesma clareza", "o espírito que ancorava a proposta da Câmara permaneceu".

Se, como já afirmou Mauro Porto, a visão de mundo hoje está sendo constituída por aquilo que o homem vê na televisão, Ismar de Oliveira Soares fala dos passos inaugurais: "a leitura e a recepção crítica dos meios têm sido entendidas como condição prévia para a leitura do mundo e a preparação para a defesa da democracia, a livre expressão do pensamento e o exercício da cidadania". E vai mostrando os artigos da Lei que tratam do tema.

Adílson Odair Citelli, em A escola e os discursos não-didáticos, trata da circulação dos discursos verbais e não-verbais no âmbito da escola, apontando a necessidade da convivência de ambos os discursos.

Mostra dados da pesquisa sobre as relações dos alunos com os meios de comunicação e vai compondo sua análise a partir de vários enfoques. Por exemplo: "se cabe analisar com os alunos porque todos cantam as mesmas

4. A revista Comunicação \& Educação n. 1, que circulou em setembro de 1994, dedicou um grande espaço para o tema, incluindo, entre outros, a entrevista com Duda Mendonça: Como se faz uma campanha política.

5. Ver o artigo: A nova $L D B$ e a formação de profissionais para a inter-relação Comunicação/Educação. Comunicação \& Educação, n.2, jan/abr, 1995. p.21-27. 
músicas, é preciso saber qual a razão que impede sejam as outras tantas cantadas ou tocadas", diz o autor. Ele considera, ainda, a necessidade de envolver os alunos nos aspectos propriamente de produção, tornando-os agentes do veículo: "elaboração de programas, realização de pequenas reportagens na área onde está localizada a escola, seleção de músicas, criação de novos produtos para serem transmitidos pelo rádio etc.".

O videogame ${ }^{6}$ faz parte dessas linguagens do mundo dos alunos. Teve uma rápida difusão e parece ter ocupado o lugar dos "jogos clássicos, como o tabuleiro, as bicicletas, carrinhos, bonecas etc.". Para tratar deles, era preciso conhecê-los e praticá-los. Foi o que fez Luciano Biagio Toriello, que nos conta tudo em Videogame, escola e conto popular.

$\mathrm{O}$ autor procura comparar os heróis dos videogames aos heróis tradicionais como Zorro, O Príncipe Valente e tantos outros.

Para tanto, serve-se do livro de Vladimir Propp, o clássico Morfologia do conto maravilhoso. Vale a pena acompanhar as descobertas do Luciano. Talvez elas nos permitam entender um pouco mais a geração do videogame.

\section{ARTIGO INTERNACIONAL}

Este número traz há a tradução do artigo $A$ violência nos meios de comunicação, do Centro para o Estudo da Comunicação e Cultura, da Universidade de Saint Louis, EUA.

As pesquisas, realizadas em várias partes do mundo, discutem questões de base, como por exemplo: "as considerações sobre a violência na televisão não deveriam se limitar à violência física, uma vez que o cinismo e a violência socialmente estruturada também são traumáticos". Elas colocam também problemas que têm se revelado parte de nosso cotidiano enquanto educadores: qual a relação entre a violência da televisão e a agressividade das crianças? Segundo alguns pesquisadores, "assistir a cenas de violência aumenta a agressão, mas crianças agressivas também escolhem programas mais violentos".

$\mathrm{O}$ assunto é altamente complexo. Vale a pena conhecer as pesquisas realizadas e a bibliografia já produzida sobre o tema.

\section{ENTREVISTA}

Neste número, Roseli Fígaro entrevista o educador Prof. Dr. Dermeval Saviani. Homem conhecido pela sua capacidade de "unir ação ao pensamento e ao sentimento", Dermeval Saviani começa nos mostrando, em Brasil: educação para a elite e exclusão para a maioria, a "protelação, por parte de

6. A palavra videogame aparece no Dicionário Aurélio como estrangeirismo, grafada na forma original video game. Adotamos, porém, a grafia que já vem sendo utilizada pela imprensa - videogame -, sem indicação de estrangeirismo, por analogia a videoclipe, videocassete etc. 
nossas elites, da instauração de um sistema nacional de educação". É sobre essa base que o educador vai abordar questões como Parâmetros Curriculares Nacionais, fixação de uma carreira para o magistério, utilização do livro didático e das novas tecnologias, Plano Decenal de Educação para Todos, entre muitos outros temas.

\section{CRÍTICA}

A beleza de Patrícia Pillar no papel da Luana do Rei do gado, novela de Benedito Rui Barbosa que está sendo apresentada pela Rede Globo, chama a atenção. Por que achamos Luana tão bonita e por que ela é tão loura? Essas duas questões se inter-relacionam ou são independentes? Isso é o que Maria Cristina Castilho Costa aborda em Luana, loura de olhos claros.

Maria Lourdes Motter fala de cinema em $O$ carteiro e o poeta: a força da poesia o filme. A crítica que constrói vai nos revelando a "corrente invisível" que "liga seres e personagens na construção de uma intertextualidade que ata no filme o dialogismo e a polifonia que ressoam na aridez bucólica da praia, da montanha, da natureza na sua pureza rude que o homem não conspurcou, presente também nos pescadores e demais habitantes da ilha".

E a construção da crítica vai-se erguendo, tijolo a tijolo, "num desenho mágico" que nos faz ver "o sentido entranhado nas coisas e seu movimento".

Vale a pena ver o filme, ler a crítica, ler o livro.

\section{DEPOIMENTO}

Quem não pôde assistir, certamente ouviu falar. A peça Bella Ciao, de Luís Alberto de Abreu, foi um grande sucesso. E essa é uma das 21 peças desse dramaturgo.

Afinal, quem é Luís Alberto? O que o levou para o teatro? Que tipo de relação ele mantém com o teatro e com a criação? Tudo isso ele conta em A trajetória de um dramaturgo.

\section{EXPERIÊNCIA}

Segundo Ivanhoé Robson Marques Bonatelli, "puxando o peixe para o mar da língua portuguesa e literatura, o nó a desatar é o seguinte: existe um conteúdo mínimo a ser seguido pelo professor, existe o aluno com sua bagagem e seu atlas de referências individuais, e o mútuo desconforto entre as partes". Que fazer?

É disso que ele nos fala em Sala de aula, sala de estar da canção popular brasileira, mostrando-nos como as letras das músicas populares (as mais diversas) podem ser a ponte entre os mundos, transformando "desconforto" em prazer. 


\section{POESIA}

Pablo Neruda é personagem do filme $\mathbf{O}$ carteiro e o poeta. Poeta chileno, dedicou sua vida à construção de uma humanidade mais plena de igualdade. Morreu logo após o golpe militar de Pinochet. É dele a poesia deste número: Los libertadores.

\section{SERVIÇOS}

Dez anos de uma nova proposta acadêmica, de Mauro Bellesa, conta a história de uma das mais importantes instituições da Universidade de São Paulo: o Instituto de Estudos Avançados (IEA).

Certamente alguns desses grupos (áreas, Grupos de Trabalho, Programas, Cátedras, Núcleos e Comissões Científicas) deve interessar a você. Para conseguir as publicações, basta comunicar-se com o IEA.

Márcia Furtado Ribeiro de Souza apresenta-nos o Instituto Astronômico e Geofísico da USP, que está completando 100 anos. Todos podem usufruir desse Instituto. Basta agendar a visita.

Guia Prático sobre Ensino e Educação com Igualdade de Gênero, escrito por Rosa Ester Rossini et al, apresenta-nos a obra feita pelo NEMGE (Núcleo de Estudos da Mulher e Relações Sociais de Gênero) Ensino e Educação com Igualdade de Gênero na Infância e Adolescência: Guia Prático para Educadoras e Educadores.

Esse livro constitui-se em um marco para a discussão sobre os estereótipos de gênero. Traz também propostas de trabalho que enriquecem as atividades de sala de aula, colaborando para a efetivação da igualdade entre as pessoas.

\section{BOLETIM BIBLIOGRÁFICO}

Em Videografia, Maria Ignês Carlos Magno escolheu o tema América Latina. Cada vez mais importante. A Bibliografia Especializada sobre a telenovela brasileira, de Anamaria Fadul, e a Bibliografia especializada na área de Comunicação e Educação, de Ismar de Oliveira Soares continuam presentes, prestando grandes serviços para que possamos pensar essas realidades a partir das reflexões existentes.

\section{UMA BOA NOTÍCIA}

A revista Comunicação \& Educação chega à Internet. Incentivado pela Diretora Editorial, planejado por Roseli Fígaro, executado por Renata 
Cristian Mattar Bonato, do Núcleo de Informática em Comunicações e Artes (NICA) da ECA-USP, rompemos barreiras, levantamos fronteiras e colocamo-nos ao acesso dos que quiserem. Sejam bem vindos à nossa home page: http://www.eca.usp.br/eca/publicacoes/comueduc/rcabert.htm

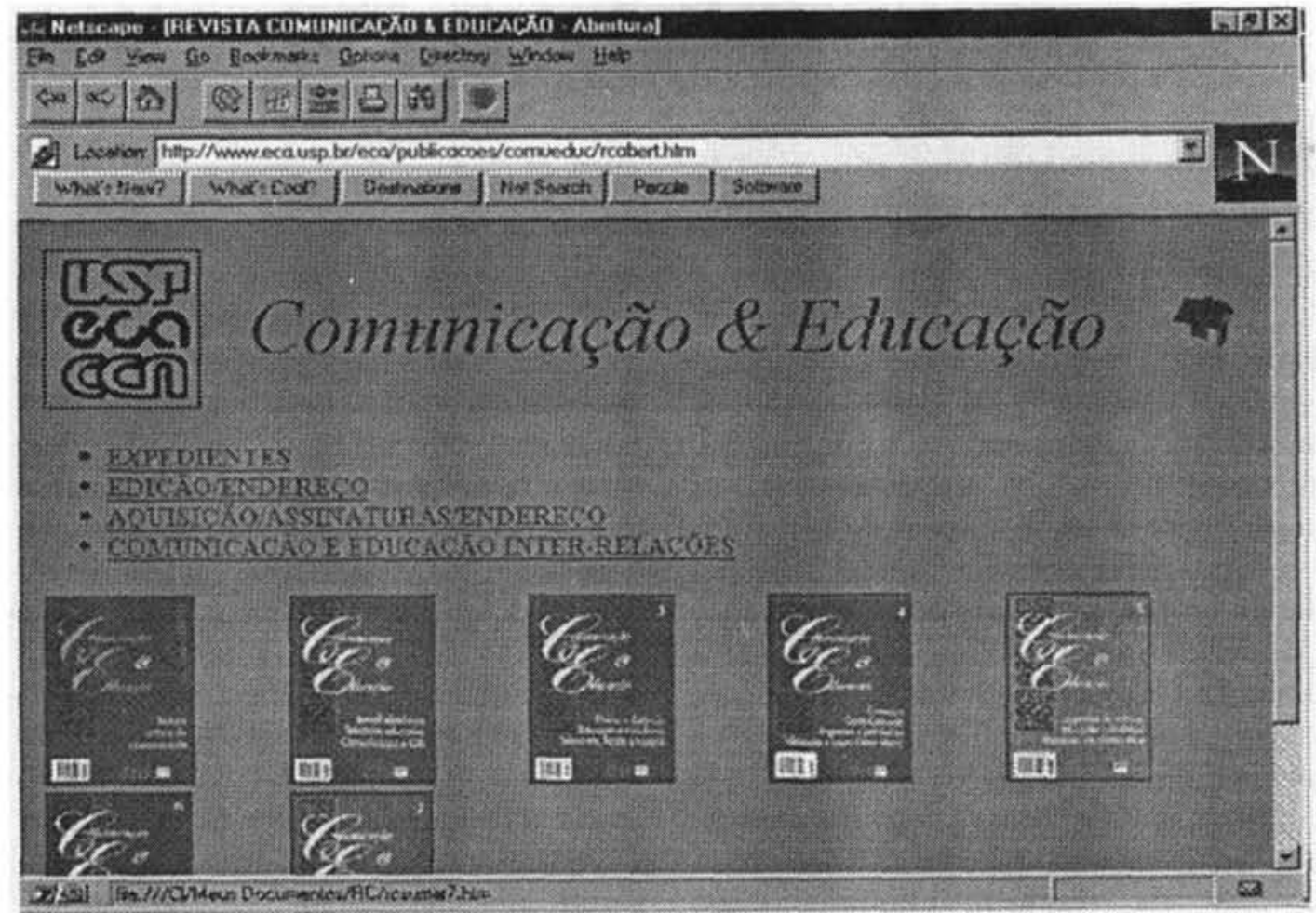

Página de abertura da home page da revista Comunicação \& Educação na Internet 